\title{
Can Youth Health Care Scans at the Age of Five Discriminate between Adolescent Psychiatric Inpatients with Severe Disruptive Behavior and a Non-Treatment Group?
}

\author{
Sjoukje Berdina Beike de Boer ${ }^{1,2 *}$, Albert Eduard Boon ${ }^{1,2,3}$, Anna Marte de Haan ${ }^{2}$ \\ ${ }^{1}$ De Fjord, Center of Orthopsychiatry and Forensic Youth Psychiatry, Lucertis, Capelle aan den IJssel, \\ The Netherlands \\ ${ }^{2}$ De Jutters, Center of Youth Mental Healthcare Haaglanden, The Hague, The Netherlands \\ ${ }^{3}$ Department of Child and Adolescent Psychiatry, Curium-Leiden University Medical Center, Leiden, The \\ Netherlands \\ Email: *s.deboer@lucertis.nl
}

Received August $13^{\text {th }}, 2013$; revised September $12^{\text {th }}, 2013$; accepted October $15^{\text {th }}, 2013$

\begin{abstract}
Copyright (C) 2013 Sjoukje Berdina Beike de Boer et al. This is an open access article distributed under the Creative Commons Attribution License, which permits unrestricted use, distribution, and reproduction in any medium, provided the original work is properly cited.
\end{abstract}

\begin{abstract}
The aim of the study was to examine whether adolescent psychiatric inpatients $(n=24)$ with severe disruptive behavior could be discriminated from a control sample $(n=41)$ based on information about disruptive behavior recorded early in their lives. Remarks by teachers and health professionals made in youth health care files when the respondents were five years of age were used. Both teachers and professionals made significantly more remarks regarding disruptive behavior in the files of the future patients. The files of the patients also contained more remarks about other behavior. The sensitivity and specificity of behavior at the age of five to predict future treatment was satisfactory. The majority of the inpatients belonged to the prototypical life-course-persistent group that is known from epidemiological studies.
\end{abstract}

Keywords: Adolescent Psychiatry; Life-Course-Persistent; Antisocial Behavior; Youth Health Care Files

\section{Introduction}

Epidemiological research (Moffitt, 1993, 2003) has shown that a relatively small part of the population (6.2\%) was engaged in antisocial behavior at a very young age which persisted at every stage in their life. This group was labeled life-course-persistent (LCP). A larger group (23.6\%) was found to be involved in antisocial behavior during adolescence only and therefore their behavior was labeled adolescence-limited (AL). Although during adolescence both groups did not differ in frequency and seriousness of offending, Moffitt (Moffitt, 1993, 2003; Moffitt \& Caspi, 2001) argued that they differed in etiology, developmental course, prognosis and classification of their behavior as either pathological (LCP) or normative (AL). Extensive support for these prototypes and their relevance for etiology, developmental processes, and prevention priorities was found (Odgers et al., 2008). By labeling children with early onset of antisocial behavior as "life-course-persistent", the epidemiological researchers implied that this group would hardly benefit from treatment or at least are in need of more intensive treatment. However, thus far this consequence has barely been tested in treatment research, nor have findings from epidemiological research been put to practical use for inpatient or forensic settings.

Present study concerned adolescents with antisocial behavior that were treated in a residential orthopsychiatric treatment facility for severe disruptive behavior combined with psychiat-

\footnotetext{
*Corresponding author.
}

ric disorders. For prognostic purposes it would be relevant to know whether these inpatients belonged to the LCP or the AL group. Therefore the question arose whether it was possible to determine if the patients' disruptive behaviors were present in early life based on retrospective data. At the moment of treatment, no reliable data about their disruptive behavior earlier in life or about the age of onset of this behavior were available. Anamnestic information gathered at admission is often subjective and unreliable: patients themselves are no reliable source on their early history and the parents' view on their child's development is often biased by their child's current condition. Therefore more objective sources of information on the child's early behavior were required. For the present study the information about the childhood disruptive behavior was drawn from youth health care files to examine its use for diagnostic purposes. The information in these files was gathered at fixed points in the child's life by youth health care professionals. In the Netherlands, Youth Health Care (YHC) offers basic care to all children from birth until the age of nineteen. This system already exists for over a hundred years and is unique in the world. The care is offered free of charge and 95\% of all children is reached. YHC is aimed at the growth and development of the child and monitors the physical, mental, social and cognitive development of children. Traditionally, the emphasis was on the physical development of the child, but in recent years, educational and psychosocial problems were also taken into account (AJN, 2009). From age five on, the schoolteacher of the second grade is asked which children need extra attention. 
If a child is in need of extra attention, the remarks of the teacher are recorded in the YHC files.

\section{Aim of the Study}

The question addressed in this paper was whether the distinction between subjects who received residential treatment for disruptive behavior during adolescence and a non-treatment control group could be made on the basis of information in the YHC files gathered at an early age. Remarks indicating disruptive behaviors at the age of five of the patients and a control group were compared to determine whether the patients already displayed more disruptive behavior in early childhood. It was hypothesized that at the age of five more signs of disruptive behavior would have been reported by the YHC workers as well as the teachers in the YHC files of the inpatients compared to the non-treatment group.

Currently some research has been conducted to determine whether the epidemiological findings regarding LCP antisocial behavior apply within a clinical sample (De Boer, Boon, Verheij, \& Donker, 2013; De Boer, Van Oort, Donker, Verheij, \& Boon, 2012; De Boer, Verheij, \& Donker, 2007). The question arose whether the distinction between individuals on the LCP and AL trajectories of antisocial behavior could be made in an inpatient sample of adolescents treated in an orthopsychiatric facility, based on retrospective data of youth health care files. This is relevant because in orthopsychiatric settings adolescents are treated who are contraindicated for regular psychiatric treatment because of their severe disruptive behavior. During adolescence these inpatients meet the broad criteria that are used in epidemiological studies on antisocial behavior. Therefore, if this behavior started early in life, they meet the criteria of the LCP group. It has been demonstrated that orthopsychiatric treatment is effective (Boon \& De Boer, 2007), so when inpatients could be assigned to the LCP group, this would indicate that they are treatable and for that reason the term life-coursepersistent is too pessimistic. The information about disruptive behaviors used to assign the patients to the LCP group is taken from notes written down in their YHC files when the children were about five years of age. Due to the complexity of the disruptive behaviors and psychiatric disorders of the sample, it was expected that a relatively high prevalence of LCP would be found.

\section{Method}

\section{Setting}

Present study was conducted at De Fjord, an orthopsychiatric and forensic psychiatric youth facility near Rotterdam. In The Netherlands, orthopsychiatric facilities offer treatment to adolescents and young adults who have psychiatric disorders combined with severe disruptive behavior. Besides day treatment and outpatient treatment, De Fjord offers a specialized treatment program to 32 adolescent inpatients. The treatment program consists of various therapies and training activities, for instance, cognitive behavioral therapy, psycho-motor therapy, art therapy, drama therapy, family therapy, social skills training, aggression regulation training, job training, and education. A cognitive-behavioral treatment model is applied with an emphasis on enhancement of social competence (Bartels, 2001) extended by elements of the scheme-based therapy (Young, Klosko, \& Weishaar, 2004), as developed by Young (Young,
1990). The facility offers treatment to both boys and girls, but boys are the majority.

\section{Sample/Participants}

\section{The Orthopsychiatric Sample}

Of the 49 inpatients that agreed to participate, only 24 health care files could be used. Of 13 patients (27\%) the files could not be traced and of 12 patients (24\%) the information about the examination in the second grade was missing. In present study, the orthopsychiatric sample of which the YHC information could be used was comprised of 10 female and 14 male inpatients, born between 1983 and 1992 that were admitted to De Fjord between 2001 and 2008. The average age at admission was 17.3 year (SD = 1.13 year; range 15 - 19 year). They were referred to the orthopsychiatric residential treatment facility by child and adolescent psychiatric institutions, youth care or judicial institutions. About a third was judicially imposed. The patients had an average 2.6 clinical diagnoses (axis I; range 1 - 5, SD 1.24). Patients were diagnosed with conduct disorders, oppositional defiant disorder, schizophrenia and related disorders, mood disorders, pervasive developmental disorders and Attention Deficit Hyperactivity Disorder (APA, 2001). Although the level of intelligence (mostly measured at the institutions that requested the admission) of the sample was about average, compared to the general population the educational attainment was relatively low.

\section{The Control Sample}

The control group was selected from the general population and was matched to the inpatient sample based on gender and year of birth (between 1983 and 1992). Only respondents with no reported history of behavioral or psychiatric disorders were selected. It was attempted to trace 55 files, of those 7 (13\%) could not be traced and of 7 files (13\%) the information about the examination in the second grade was missing. The control group used in present study consisted of 25 males and 16 females.

\section{Procedure}

After a verbal description of the study to the subjects, written informed consent was obtained to gather information from their YHC files. Respondents of the patient group were informed that they could refuse cooperation without any consequence for their treatment. The YHC files, in which all information was recorded, were usually stored at the Municipal Public Health Service (MPHS) of the district where the child resided at the age of twelve. Every MPHS used the same file format, with standard (sub) headings to register notes (e.g. length, weight, illnesses, speech, hearing, temper tantrums). Of both samples, the YHC files were requested at the designated MPHS. The tracked files were viewed by the researchers at the office of the MPHS, and screened on remarks on behavior problems. Because many of the obtained files were incomplete on a later age, it was decided to focus the study on the information of the health scans at the second grade (the nursery school part) of the Dutch school system. In the YHC procedure this was the first time that teachers were asked which children needed extra attention because of concerns about their health or behavior. Children were also examined by a doctor or nurse. In present study the remarks of teachers and the amnesic information from 
the health care doctor or nurse were used. The YHC professsionals had to use a format with defined headings: "Appetite", "Sleep”, “Toilet training”, "Playing solo”, "Playing with others”, "General impression", "Pathology" and "Psychosocial functioning". Apart from the remarks written under these headings, the files also contained additional remarks on developmental issues that were considered relevant by the teachers and the health care professionals. All of these, often sketchy written, remarks were categorized by the researchers in four categories: "Remarks indicating disruptive behavior", "Positive remarks", "Neutral remarks" and "No remarks". Examples of remarks indicating disruptive behavior were: "Bad concentration, doesn't listen", "Motivation and behavior problems", "Black sheep because of aggression”, "Needs a lot of attention”, "Has many conflicts", "Very noisy child". All remarks like "Does very well", "She likes school", "Has many friends" were labeled positive. All other remarks like: "Wears glasses", "Does often have a cold", "Sight of left eye needs attention" were seen as neutral from the perspective of this study. The remarks were categorized without knowledge of the background (patient or control) of the respondent. The categorized remarks from teachers and health care practitioners concerning the inpatients and the controls were compared. Children with one or more "remarks indicating disruptive behavior” before or at age five were considered as possibly belonging to the LCP group.

\section{Statistical Analysis}

All analyses were performed using the Statistical Package for the Social Sciences, version 17.01 (SPSS, 2008). Chi-square tests were used to examine differences in categorical variables. ROC-curves were calculated to investigate the sensitivity and specificity of the remarks from teachers and YHC professionals in discriminating the inpatient and the control group.

\section{Results}

Both the number $\left(X^{2}(1,65)=15.1, p=.000\right)$ and the nature $\left(X^{2}(3,65)=19.2, p=.000\right)$ of remarks made by teachers (see Table 1) on the patients and on the control group differed significantly. The remarks made by the health care professionals (see Table 1) only differed in nature $\left(X^{2}(3,65)=17.1, p=.001\right)$ between patients and controls.

Subsequently, the remarks of the teachers and the health care professionals were compared $\left(X^{2}\right)$ and although there were large differences in the number of times any remarks were given, no differences were found between the two groups of evaluators.

Table 1.

Comparison of health care professionals' remarks about inpatients and control group.

\begin{tabular}{ccccccc}
\hline & \multicolumn{2}{c}{ Inpatients } & \multicolumn{2}{c}{ Controls } & \multicolumn{2}{c}{ Total } \\
\cline { 2 - 7 } & $\mathrm{n}$ & $\%$ & $\mathrm{n}$ & $\%$ & $\mathrm{n}$ & $\%$ \\
\hline $\begin{array}{c}\text { Positive remarks } \\
\begin{array}{c}\text { Remarks disruptive } \\
\text { behavior }\end{array}\end{array}$ & 7 & 29 & 22 & 54 & 29 & 45 \\
$\begin{array}{c}\text { Neutral remarks } \\
\text { No remarks }\end{array}$ & 5 & 21 & 11 & 27 & 16 & 25 \\
Total & 0 & 0 & 5 & 12 & 5 & 8 \\
\hline
\end{tabular}

Table 2.

Comparison of teachers' remarks about inpatients and control group.

\begin{tabular}{ccccccc}
\hline & \multicolumn{2}{c}{ Inpatients } & \multicolumn{2}{c}{ Controls } & \multicolumn{2}{c}{ Total } \\
\cline { 2 - 7 } & $\mathrm{n}$ & $\%$ & $\mathrm{n}$ & $\%$ & $\mathrm{n}$ & $\%$ \\
\hline Positive remarks & 6 & 25 & 7 & 17 & 13 & 20 \\
$\begin{array}{c}\text { Remarks disruptive } \\
\text { behavior }\end{array}$ & 10 & 42 & 2 & 5 & 12 & 19 \\
Neutral remarks & 3 & 12 & 3 & 7 & 6 & 9 \\
No remarks & 5 & 21 & 29 & 71 & 34 & 52 \\
Total & 24 & 100 & 41 & 100 & 65 & 100 \\
\hline
\end{tabular}

Less than thirty percent of the files of the control group contained remarks from the teachers, opposed to about eighty percent of the inpatients files (see Table 2).

The percentage of teachers' remarks indicating disruptive behavior of the patients was eight times higher than that of the control group. Of the patient group, ten individuals (42\%) had a remark indicating disruptive behavior, in the control group this was the case for two children (5\%). For the health care professionals the difference in the number of remarks between the inpatient group and the control group was much smaller. This was probably due to the fact that the professionals had to fill in prearranged categories, while the teachers' remarks were only recorded when something was considered wrong with the child. The percentage remarks given by the YHC professional indicating disruptive behavior of the inpatients was almost seven times higher than that of the control group. Of the inpatient group twelve individuals (50\%) had a remark indicating disruptive behavior, while for the control group this was the case for three children (7\%).

To examine whether information from YHC files could be used as a predictor for orthopsychiatric treatment later in life, a ROC curve analysis was made (see Figure 1).

The remarks of both teachers and YHC professionals were allocated to the following values: 1 "No remarks", 2 "Neutral remarks", 3 "Positive remarks", 4 "Remarks indicating disrupttive behavior". Belonging to the inpatient group was the state variable. The area's under the curve (AUC), indicating sensitivity (the probability that a child with disruptive behavior at the age of five will belong to the orthopsychiatric sample) and specificity (the probability that a child without disruptive behavior at the age of five will belong to the control group) was significant. For the teachers' remarks the AUC was .79 ( $p$ $=.000,95 \% \mathrm{CI}=.67-.91)$, for the YHC professionals' remarks the AUC was $.73(p=.001,95 \% \mathrm{CI}=.59-.86)$. The sensitivity of the teachers remarks was .42 and the specificity .70 when "remarks about disruptive behavior" was taken as a criterion. When "any remark of the teacher" was taken as the criterion, sensitivity was .79 and specificity .95 . The sensitivity of the YHC professionals remarks was .50 and the specificity .92 when "remarks about disruptive behavior" was taken as a criterion. When "any remark of the doctor or nurse" was taken as the criterion, sensitivity was 1.00 and specificity .12 .

\section{Discussion}

The theoretical framework of present study concerned the distinction between individuals with life-course-persistent and adolescence-limited antisocial behavior. In this light, the main 


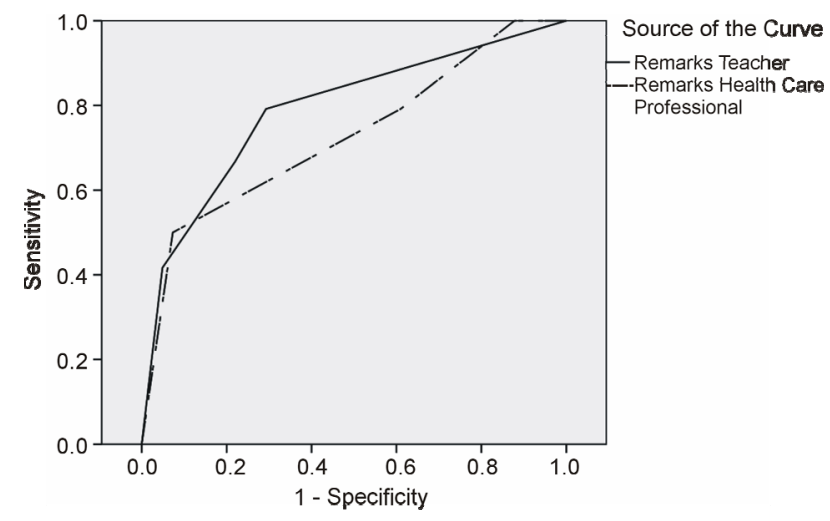

Figure 1.

ROC curves of the predictive value for residential treatment during adolescence of teachers' and health care professionals' observations of disruptive behaviour at age 5 .

goal of this paper was to examine whether an adolescent inpatient group differed from a matched, non-treatment control group on information about early disruptive behavior registered in youth health care (YHC) files. These files contained information that had been gathered at fixed times from birth to age nineteen, and were therefore considered usable to determine early onset of disruptive behavior reliably. Because much information of a later age was missing in the files, the study focused on information of health scans at the second grade, when the infant was about five years of age.

The first finding was that of the inpatient group over half of the files could not be used, because either the files were untraceable or the information about the examination in the second grade was missing. Of the control group, the percentages of untraceable or unusable data were about half as high. There may be several reasons why files were missing or incomplete. Parents may have refused to cooperate with the youth health care examination, or files can be untraceable because of frequent rehousing of the family or the child. It was unclear what happened to a file if a child was not at school, for instance in case of institutionalization. Although the exact reasons for untraceability of the files remained unknown, it should be considered as a first indication that the early lives of the children that would be institutionalized during adolescence were more turbulent and complicated than those of the controls.

Because the remarks of the teachers were only registered when he or she thought the child needed extra attention, the fact that majority of the inpatient group had a remark of any kind, compared to about only one third of the control group, is an indication that the inpatients already differed from their peers at a very young age. The fact that special attention had been asked for some children, but the remarks in the YHC file were positive or neutral, indicates that the files probably did not always adequately reflect the reason for extra attention.

For the inpatient group, both teachers and health care professionals have reported much more disruptive behavior. This indicates that, based on the observations at the age of five and the fact that the inpatients displayed severe disruptive behavior in adolescence, at least about half of the inpatients probably belonged to the LCP group. Only a minority (7\%) of the control group displayed disruptive behavior at age five, and because the controls were selected on their absence of behavioral problems in adolescence, the problems mentioned at the age of five were probably temporarily. The data do not allow conclusions regarding children who did not display disruptive behavior in the second grade. Although the literature is inconclusive about the upper limit in the age of onset of LCP disruptive behavior (e.g. age 8 , age 10 , age 12 ), the possibility exists that the group that showed no signs of disruptive behavior at the second grade, did develop this behavior later on during primary school.

It is concluded that within the group that would eventually be treated in the orthopsychiatric residential setting, signs of disruptive behavior were already observed at the age of five by teachers or health care professionals for about half of the respondents. In this aspect, they differed significantly from the control group. More attention should be paid to children that show signs of disruptive behavior at this early age. Although epidemiological researchers labeled this group as life-coursepersistent, ergo untreatable (Moffitt, 2003; Moffitt \& Caspi, 2001; Moffitt, Caspi, Harrington, \& Milne, 2002), they can profit from early interventions. Children with untreated behavioral problems are more likely to drop out from school, engage in delinquent activities, drug and alcohol abuse and unemployment (Lochman \& Salekin, 2003; Odgers et al., 2008).

Recently the storage of information of the youth health care files in The Netherlands has been improved. Digitized storage will hopefully lead to more accurate and traceable information, so in the future more clarity about the differentiation of adolescent residential inpatients in life-course-persistent and adolescence-limited groups can be reached and the treatment programs for these groups can be further specialized.

\section{Limitations}

This study has several limitations. First, although the results of the inpatient group compared to the control group are convincing, the number of inpatient files that could be included in the study is rather small. The second limitation of this study is that, although we know from a large minority of inpatients that they showed signs of disruptive behavior at a young age, no information is available of the development of these children at a later primary school age or during early adolescence.

\section{Acknowledgements}

The authors wish to thank Danielle Beekenkamp, Judith Meerman and Danicia Tjwa, students at the "The Hague University", who collected part of the inpatient data and all of the control group data from the Youth Health Care files for their bachelor thesis. The authors also acknowledge the inpatients and adolescents who consented to participate, Zita Haijer, who as manager at De Fjord enabled the study, and Jos Leenes and Amos Daal for providing the essential literature.

\section{REFERENCES}

AJN (2009). Youth Health Care for next to nothing. Nieuwsbrief van Artsen Jeugdgezondheidszorg Nederland, 2, 7.

APA (2001). Diagnostic and statistical manual of mental disorders (4th ed.). Washington, DC: American Psychiatric Association.

Bartels, A. (2001). The social competence model and the child and youth psychotherapy: Origin, meaning, state of affairs and future. Kinderen Jeugdpsychotherapie, 28, 5-22.

Boon, A., \& De Boer, S. (2007). Drug usage as a threat to the stability of treatment outcome. European Child \& Adolescent Psychiatry, 16, 79-86. http://dx.doi.org/10.1007/s00787-006-0576-x

De Boer, S., Boon, A., Verheij, F., \& Donker, M. (2013). Characteris- 


\section{S. B. B. DE BOER ET AL.}

tics of adolescent psychiatric inpatients with early-onset and adolescent-onset disruptive behavior. International Journal of Forensic Mental Health, 12, 14-25.

http://dx.doi.org/10.1080/14999013.2012.760183

De Boer, S., Van Oort, F., Donker, M., Verheij, F., \& Boon, A. (2012). Childhood characteristics of adolescent inpatients with early-onset and adolescent-onset disruptive behavior. Journal of Psychopathology and Behavioral Assessment, 34, 415-422. http://dx.doi.org/10.1007/s10862-012-9283-8

De Boer, S., Verheij, F., \& Donker, M. (2007). What do youth health care files have to hide from us? A study into signs of later behavioral problems. Maandblad Geestelijke Volksgezondheid, 62, 640-649.

Lochman, J., \& Salekin, R. (2003). Introduction prevention and intervention with aggressive and disruptive children: Next steps in behavioral intervention research. Behavior Therapy, 34, 413-419. http://dx.doi.org/10.1016/S0005-7894(03)80027-8

Moffitt, T. (1993). Adolescence-limited and life-course-persistent antisocial behavior: A developmental taxonomy. Psychological Review, 100, 674-701. http://dx.doi.org/10.1037/0033-295X.100.4.674

Moffitt, T. (2003). Life-course-persistent and adolescence-limited antisocial behavior: A 10-year research review and a research agenda. In
B. Lahey, T. Moffitt, \& A. Caspi (Eds.), Causes of conduct disorder and juvenile delinquency (pp. 49-75). New York: The Guilford Press. Moffitt, T., \& Caspi, A. (2001). Childhood predictors differentiate life-course persistent and adolescence-limited antisocial pathways among males and females. Development and Psychopathology, 13, 355-375. http://dx.doi.org/10.1017/S0954579401002097

Moffitt, T., Caspi, A., Harrington, H., \& Milne, B. (2002). Males on the life-course-persistent and adolescence-limited antisocial pathways: Follow-up at age 26 years. Development and Psychopathology, 14, 179-207. http://dx.doi.org/10.1017/S0954579402001104

Odgers, C., Moffitt, T., Broadbent, J., Dickson, N., Hancox, R., Harrington, H., et al. (2008). Female and male antisocial trajectories: From childhood origins to adult outcomes. Development and Psychopathology, 20, 673-716.

http://dx.doi.org/10.1017/S0954579408000333

SPSS (2008). SPSS 17.0 family.

Young, J. (1990). Cognitive therapy for personality disorders: A schema-focussed approach. Sarasota, FL: Professional Resource Press.

Young, J., Klosko, J., \& Weishaar, M. (2004). Scheme based therapy: Manual for therapists. Houten: Bohn Stafleu van Loghum. 